\title{
Extremely Small AWG Demultiplexer Fabricated on InP by Using a Double-Etch Process
}

\author{
Y. Barbarin, X. J. M. Leijtens, E. A. J. M. Bente, C. M. Louzao, J. R. Kooiman, and M. K. Smit
}

\begin{abstract}
A compact low-loss $4 \times 4$ arrayed waveguide grating (AWG) demultiplexer with a channel spacing of $400 \mathrm{GHz}$ is presented. By employing a double-etch process, a low-loss device is made with deeply etched waveguides that have a bending radius down to $30 \mu \mathrm{m}$. This small radius and a reduction of the number of array arms, reduces the device size to only $230 \times 330 \mu \mathrm{m}^{2}$. Measured insertion losses are less than $5 \mathrm{~dB}$ and the crosstalk is below $-12 \mathrm{~dB}$. To our knowledge, this is the smallest AWG reported to date.
\end{abstract}

Index Terms-Arrayed waveguide grating (AWG), integrated optics, PHASAR, semiconductor waveguide, wavelength-division multiplexing.

\section{INTRODUCTION}

$\mathbf{P}$ HASED-ARRAY demultiplexers [1] or arrayed waveguide gratings (AWGs) are key components for wavelength-division-multiplexing applications. Large-scale integration of this component pushes the size reduction to the limits of the current processing technology. Small polarization-independent phased-array demultiplexers have been reported with a size of $300 \times 340 \mu \mathrm{m}^{2}$ by Bissessur et al. [2] using only deeply etched waveguides and a bending radius of $100 \mu \mathrm{m}$. To further decrease the size of an AWG and to have an acceptable loss value, it is required to decrease the radius of curvature of the waveguides and to combine deeply and shallowly etched waveguides [3], [4]. The increased scattering losses introduced by the straight and curved deeply etched waveguides are compensated by the reduction of the device size. We have tested many AWGs, varying different parameters. In this letter, we present the design and the performance of the smallest: The size is reduced to $230 \times 330 \mu \mathrm{m}^{2}$. Afterwards follows an analysis of the reduction of the array acceptance factor (AAF) on AWG's crosstalk and insertion losses.

\section{DESIGN}

We have designed an extremely small four-channel AWG with a 400-GHz channel spacing $(3.2$ at $1550 \mathrm{~nm}$ ) and a freespectral range of $12.8 \mathrm{~nm}$ (Fig. 1). The minimum bending radius used for the array waveguides was $30 \mu \mathrm{m}$. Although an even smaller minimum radius could have been used, it does not significantly reduce the device size. The AWG was designed

Manuscript received May 18, 2004; revised July 13, 2004. This work was supported by the Dutch NRC Photonics Programme and by the Toward Freeband Communication Impulse of the technology programme of the Dutch Ministry of Economic Affairs.

The authors are with COBRA TU Eindhoven, Eindhoven 5600MB, The Netherlands (e-mail: y.barbarin@tue.nl).

Digital Object Identifier 10.1109/LPT.2004.835217

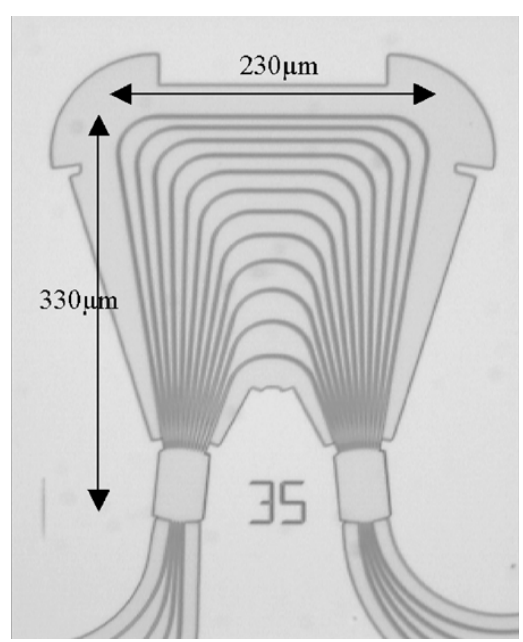

Fig. 1. Photograph of the fabricated device.

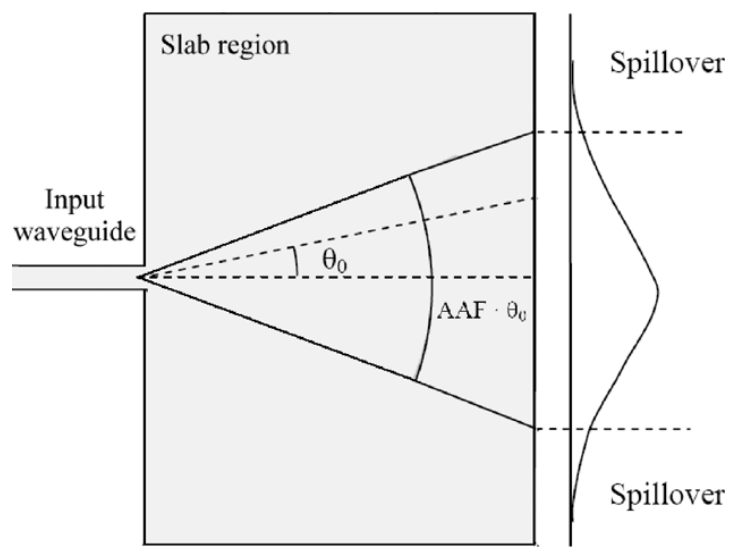

Fig. 2. Definition of the AAF a value of $\mathrm{AAF}=4$ is shown.

for a ridge waveguide structure consisting of a 720 -nm-thick InGaAsP waveguide layer (bandgap wavelength $1.25 \mu \mathrm{m}$ ) with a 1200-nm-thick InP upper cladding layer.

Next design parameter to be defined is the AAF. A definition of this parameter is plotted in Fig. 2. The beam propagating through the input waveguide and entering the slab region is no longer laterally confined and becomes divergent. The divergent beam is approximately Gaussian with a waist parameter $\theta_{0}$. Only a part of the far field is accepted by the array of arms. The corresponding far field angle divided by $\theta_{0}$ defines the AAF. In this design, the angular region corresponding to an AAF of 2.4 holds 12 array waveguides.

The first $10 \mu \mathrm{m}$ of the waveguides in the array of the small AWG, connected to the slab region (Fig. 3), are $2.0 \mu \mathrm{m}$ wide and shallowly etched (100-nm depth in the filmlayer). The 


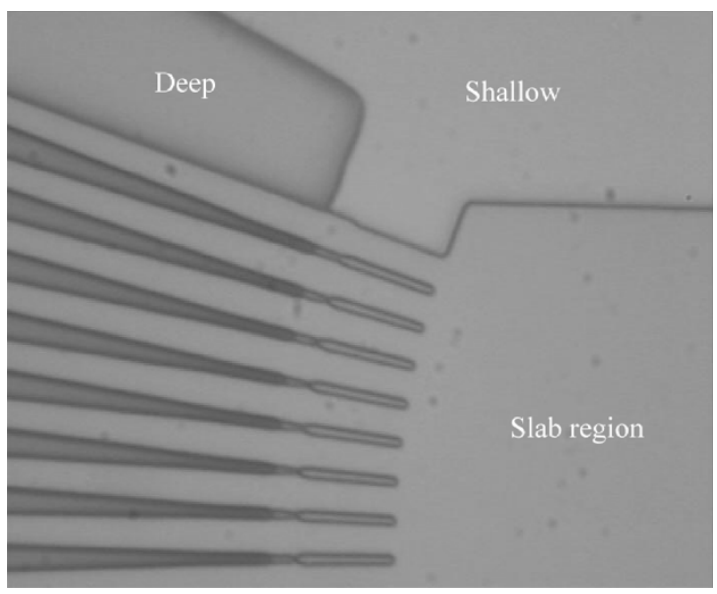

Fig. 3. Photograph of deep-shallow waveguide transition. The transition is done gradually using a 50- $\mu$ m-long taper.

array arms themselves and the input waveguides are $1.7 \mu \mathrm{m}$ wide and deeply etched (150 $\mathrm{nm}$ through the filmlayer). The deep-shallow transition is done gradually using a 50- $\mu$ m-long taper. A better coupling is obtained by using an extra width of $0.3 \mu \mathrm{m}$ between the taper and the shallow waveguide.

The device was designed for a 720-nm-thick filmlayer (bandgap wavelength $1.25 \mu \mathrm{m}$ ) and a 1200-nm-thick InP cladding layer. With this layerstack and a deeply etched waveguide width of $1.7 \mu \mathrm{m}$, the propagation constant of the fundamental mode is polarization independent. However, due to the material available, we have realized this AWG in a layer stack with a 500-nm-thick InGaAsP waveguide layer (bandgap wavelength $1.35 \mu \mathrm{m}$ ) with a 300-nm-thick InP cladding layer. Because of this change, the device is not polarization independent.

\section{FABRICATION}

The layerstack of the small AWG was grown using low-pressure metal-organic vapor phase epitaxy. A SiNx layer of $50 \mathrm{~nm}$ was deposited using plasma-enhanced chemical vapor deposition. This layer served as an etching mask for the waveguides. The pattern was defined using contact photolithography with positive photoresist and transferred to the $\mathrm{SiNx}$ layer by $\mathrm{CHF}_{3}$ reactive ion etching (RIE). Then deep areas were defined using a second contact photolithography with positive photoresist. The photoresist served as a mask for the deep etch. The deep waveguides were partly etched employing a $\mathrm{CH}_{4}-\mathrm{H}_{2}$ etching process (RIE). The depth corresponds to the difference between shallow and deep waveguides. After the resist was removed, deep and shallow waveguides were etched with the same process. The SiNx layer was removed in a buffered HF solution.

\section{MEASUREMENTS}

Losses for deeply and shallowly etched straight waveguides were measured using the Fabry-Pérot technique [5]. An average of $2.2 \mathrm{~dB} / \mathrm{cm}$ was obtained for shallowly etched straight waveguides. We obtained $5.5 \mathrm{~dB} / \mathrm{cm}$ for deeply etched straight waveguides. Losses for a 1.7- $\mu \mathrm{m}$-wide deeply etched waveguide are almost $2 \mathrm{~dB} / \mathrm{cm}$ higher than with a single etching

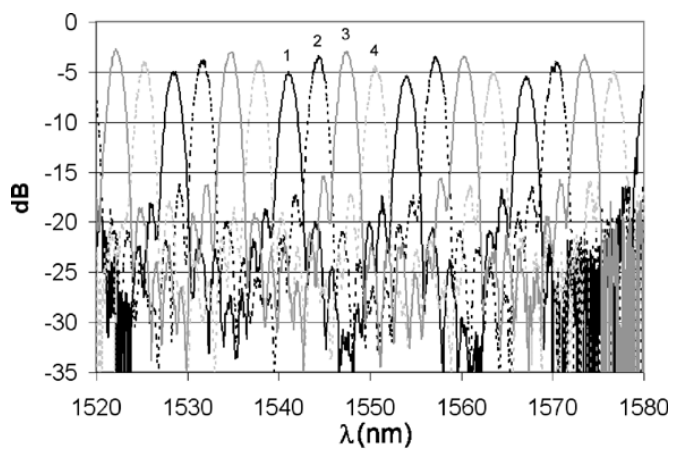

(a)

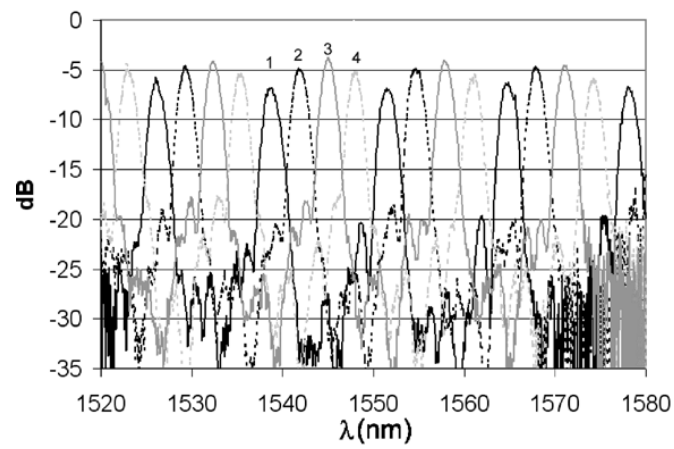

(b)

Fig. 4. Measured transmission spectra of the small AWG for (a) transverse electric and (b) transverse magnetic. As expected with a 500-nm-thick filmlayer, the device shows some polarization dependence.

process. This is due to the masking of the shallow parts by photoresist, which has introduced sidewall roughness. Losses for 2- $\mu \mathrm{m}$-wide shallowly etched waveguides are slightly higher in comparison to similar waveguides made with a single etch process.

The transmission spectrum of the small AWG was measured using the spontaneous emission spectrum of an erbium-doped fiber amplifier (EDFA) as a broad-band light source and a polarizer to select the polarization state. Light was coupled into the chip using microscope objectives, then coupled out of the waveguides by a single-mode lensed fiber and analyzed with an optical spectrum analyzer. The reference EDFA spectrum that defined the insertion loss level was determined from transmission spectra of a large number of separate good waveguides.

Fig. 4 shows the measured transmission spectra for both polarizations of the small AWG. Measured insertion losses are less than $5 \mathrm{~dB}$ and the crosstalk is below $-12 \mathrm{~dB}$. As expected, due to the fact that we used a 500-nm-thick filmlayer instead of $720 \mathrm{~nm}$, the devices have some polarization dependence in agreement with simulations. This particular device shows a 2.3-nm shift between the two polarizations. We notice a difference of $2 \mathrm{~dB}$ between the transmission of the center channel and the outer channels. This is to be expected for a periodic device.

Because of the crosstalk, the device presented is more suitable to be integrated in a multiwavelength laser (MWL) [6], [7] than in an add-drop multiplexer or an optical cross-connect. For MWL integration, the periodicity of the device requires narrow gain material centered on the transmission spectra to avoid the lasing in other free spectral range. 


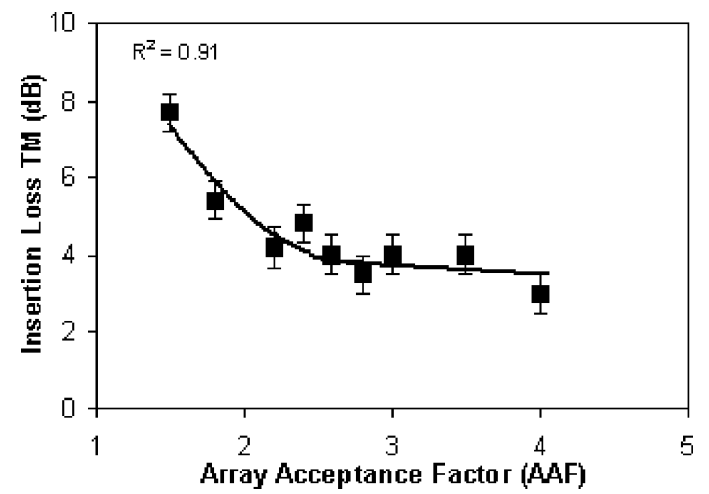

Fig. 5. Measured insertion losses versus the AAF.

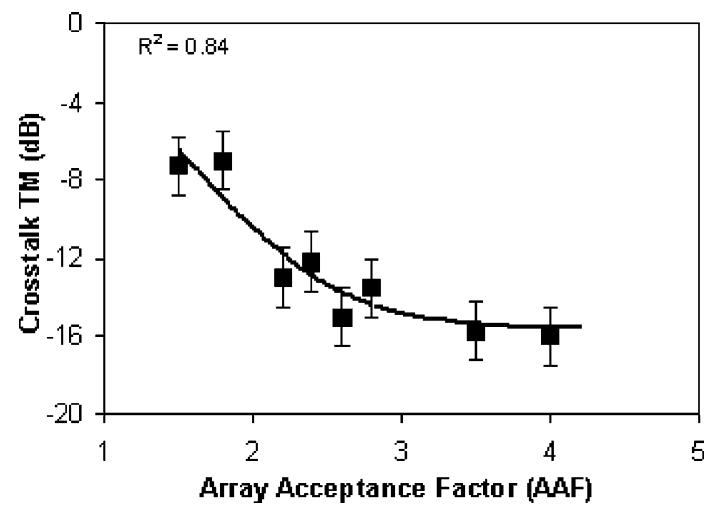

Fig. 6. Measured crosstalk versus the AAF.

\section{EFFECT OF THE REDUCTION OF THE AAF}

The AAF is an important parameter in the design of a small AWG as it determines the number of arms and, thus, the size of the device. Figs. 5 and 6 show the AAF influence on the insertion losses and the crosstalk measured from a series of AWGs with a constant a bending radius of $100 \mu \mathrm{m}$ and a design similar to the one described in [3].

The insertion loss is almost independent of the AAF for values above 2.5. Below that factor, however, the loss starts to rapidly increase. The crosstalk shows the same behavior: a clear increase for an AAF factor below 2.5. We believe that these results are independent of the bending radius and the specific design of the array arms.

The device presented above has an AAF of 2.4 and a minimum bending radius of only $30 \mu \mathrm{m}$. The measured insertion losses are less than $5 \mathrm{~dB}$ and the crosstalk is below $-12 \mathrm{~dB}$. Those values fit well with the previous graphs for this value of the AAF.

\section{CONCLUSION}

A compact low-loss $4 \times 4$ AWG demultiplexer with a channel spacing of $400 \mathrm{GHz}$ has been fabricated. The device size is only $230 \times 330 \mu \mathrm{m}^{2}$, and to our knowledge, this is the smallest AWG reported to date. Measured insertion losses are less than $5 \mathrm{~dB}$ and the crosstalk is below $-12 \mathrm{~dB}$. The device is suitable, for example, for use in very compact MWLs.

\section{REFERENCES}

[1] M. K. Smit and C. van Dam, "PHASAR-based WDM-devices: Principles, design, and applications," IEEE J. Select. Topics Quantum Electron., vol. 2, pp. 236-250, June 1996.

[2] H. Bissessur, P. Pagnod-Rossiaux, R. Mestric, and B. Martin, "Extremely small polarization independent phased-array demultiplexers on InP,' IEEE Photon. Technol. Lett., vol. 8, pp. 554-556, Apr. 1996.

[3] J. H. den Besten, M. P. Dessens, C. G. P. Herben, X. J. M. Leijtens, F. H. Groen, M. R. Leys, and M. K. Smit, "Low-loss, compact, and polarization independent PHASAR demultiplexer fabricated by using a double-etch process," IEEE Photon. Technol. Lett., vol. 14, pp. 62-64, Jan. 2002.

[4] Y. C. Zhu, F. H. Groen, D. H. P. Maat, Y. S. Oei, J. Romijn, and I. Moerman, "A compact PHASAR with low central channel loss," in Proc. 9th Eur. Conf. Integrated Optics (ECIO '99), Torino, Italy, Apr. 14-16, 1999, pp. 219-222.

[5] D. F. Clark and M. S. Iqbal, "Simple extension to the Fabry-Pérot technique for accurate measurement of losses in semiconductor waveguides," Opt. Lett., vol. 15, no. 22, pp. 1291-1293, Nov. 1990.

[6] P. J. Harmsma, M. K. Smit, Y. S. Oei, M. R. Leys, C. A. Verschuren, and H. Vonk, "Multi wavelength lasers fabricated using selective area chemical beam epitaxy," in Tech. Dig. Integrated Photonics Res. (IPR '99), Santa Barbara, CA, 1999, pp. 17-19.

[7] J. H. den Besten, R. G. Broeke, M. van Geemert, J. J. M. Binsma, F. Heinrichsdorff, T. van Dongen, E. A. J. M. Bente, X. J. M. Leijtens, and M. K. Smit, "Compact digitally tunable seven-channel ring laser," IEEE Photon. Technol. Lett., vol. 14, pp. 753-755, June 2002. 